\title{
Investigación y Ciencia đăng bài của ISR
}

\author{
Nguyễn Thanh Huyền \\ Trung tâm ISR \\ Trường ĐH Phenikaa
}

http://isr.phenikaa-uni.edu.vn/chitiet/tin-tuc 20192222758 84/investigacion-y-cienciadang-bai-cua-isr

Phenikaa-uni.edu.vn (Hà Nội, 31-10-2020)-Tạp chí Investigación y Ciencia (№ 530), số ra tháng 11-2020, đã xuất bản bài “¿Cómo retractarse en ciencia?" của Trung tâm ISR. Đây là tạp chí tiếng Tây Ban Nha do Prensa Científica (Barcelona) phát hành [1].

\section{INvestiecaior \\ CIENCIA}

\section{¿Cómo retractarse en ciencia?}

La comunidad científica debe acordar cuál es la información esencial que hay que comunicar al retirar un artículo.

(†) (2) (9) +

Quan-Hoang Vuong

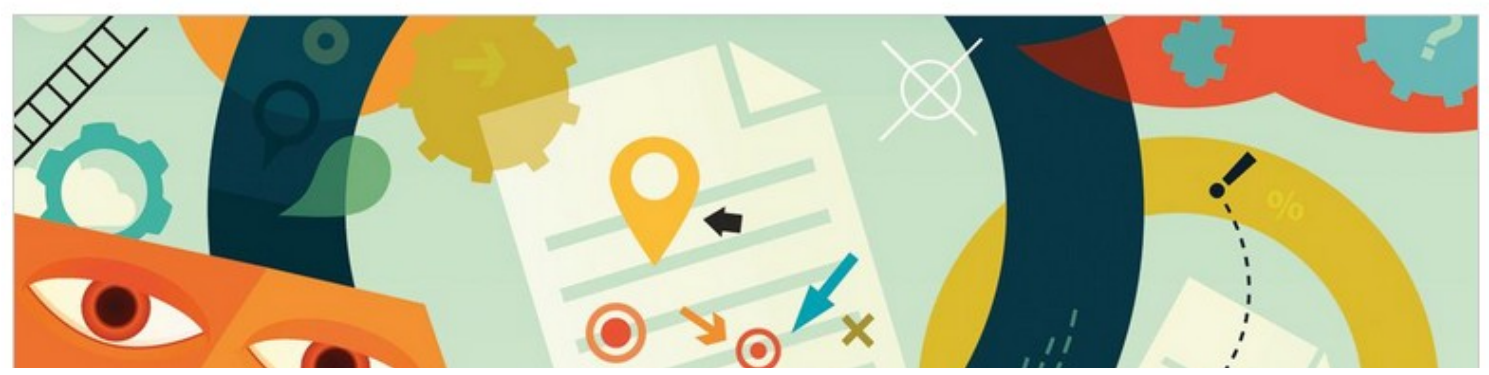

Investigación y Ciencia Noviembre 2020 
Nội dung bài báo trên phản ánh cơ bản bài trên Nature có tiêu đề "Reform retractions to make them more transparent" [2] của tác giả Vương Quân Hoàng (ISR, Phenikaa University).

Điều thú vị có thể kể đến: Kể từ 1976, Investigación y Ciencia chính là phiên bản tiếng Tây Ban Nha của tạp chí lâu đời nhất nước Mỹ Scientific American (ISSN: 0036-8733). Scientific American tới nay đã 175 năm tuổi và vẫn phát hành liên tục. Thông tin tra cứu nhanh của Google về tạp chí Mỹ cao tuổi nhất như sau (chi tiết xem Wikipedia [3]):

\section{Scientific American}

\section{Magazine \\ (4) scientificamerican.com}

Scientific American is an American popular science magazine. Many famous scientists, including Albert Einstein, have contributed articles to it. It is the oldest continuously published monthly magazine in the United States. Wikipedia

Impact factor: 1.629 (2019)

Publisher: Springer Nature

History: Since August 28, 1845; 175 years ago

Edited by: Laura Helmuth

ISO 4: Sci. Am

Discipline: Popular science

People also search for: New Scientist, Discover, Science, Nature, MORE

https://en.wikipedia.org/wiki/Scientific_American

Thông tin liên quan về nội dung ấn phẩm Investigación y Ciencia có thể tham khảo trên trang web của tạp chí [4]. 


\section{References:}

[1] Quan-Hoang Vuong. (2020). ¿Cómo retractarse en ciencia?. Investigación y Ciencia, № 530, Noviembre 2020. URL: https://www.investigacionyciencia.es/revistas/investigacion-yciencia/grandes-hitos-y-prximos-retos-de-la-ciencia-811/cmo-retractarse-en-ciencia19145

[2] Quan-Hoang Vuong. (2020). Reform retractions to make them more transparent. Nature, 582(7811), 149. URL: https://www.nature.com/articles/d41586-020-01694-x

[3] Wikipedia. (2020). Scientific American. URL:

https://en.wikipedia.org/wiki/Scientific American

[4] Investigación y Ciencia. (2020). Investigación y Ciencia. URL:

https://www.investigacionyciencia.es/paginas/quines-somos-10508 